\title{
W-Band Millimeter waves targeted mortality of H1299 human lung cancer cells without affecting non-tumorigenic MCF-10A human epithelial cells in vitro
}

\author{
Konstantin Komoshvili ${ }^{2}$, Katya Israel ${ }^{1}$, Jacob Levitan ${ }^{2}$, Asher Yahalom³, Ayan Barbora', 2 \\ and Stella Liberman-Aronov ${ }^{1^{*}}$ \\ 1 Department of Molecular Biology, Ariel University, Ariel, Israel. \\ 2 Department of Physics, Ariel University, Ariel, Israel. \\ 3 Department of Electrical \& Electronic Engineering, Ariel University, Ariel, Israel. \\ * Correspondence: stellar@ariel.ac.il; Tel.: (972) 3-937-1431 (Israel)
}

Featured Application: W Band (75 - $105 \mathrm{GHz}$ ) Millimeter-wave irradiation therapy for targeted treatment of human lung cancer without affecting non-tumorigenic human epithelial cells.

\begin{abstract}
Therapeutically effective treatments of cancer are limited. To calibrate the efficiency of the novel technique we recently discovered to modulate cancer cell viability using tuned electromagnetic fields; H1299 human lung cancer cells were irradiated in a sweeping regime of W-band (75-105 GHz) millimeter waves (MMW) at $0.2 \mathrm{~mW} / \mathrm{cm}^{2}\left(2 \mathrm{~W} / \mathrm{m}^{2}\right)$. Effects on cell morphology, cell death and senescence were examined and compared to that of nontumorigenic MCF-10A human epithelial cells. MMW irradiation led to alterations of cell and nucleus morphology of H1299 cells, significantly increasing mortality and senescence over 14 days of observation. Extended irradiation of 10 minutes duration resulted in complete death of exposed H1299 cell population within two days, while healthy MCF-10A cells remained unaffected even after 16 minutes of irradiation under the same conditions. Irradiation effects were observed to be specific to MMW treated H1299 cells and absent in the control group of non-irradiated cells. MMW irradiation did not affect cell morphology of immortalized MCF10A cells. Irradiation with low intensity MMW shows an antitumor effect on H1299 lung cancer cells. This method provides a novel treatment modality enabling targeted specificity for various types of cancers.
\end{abstract}

Keywords: W-band (75-105 GHz) MMW; H1299 human lung cancer cells; non-tumorigenic MCF-10A human epithelial cells; in vitro 


\section{Introduction}

Treatment of different types of cancer, specifically in metastatic stages is a major challenge in oncology. Major limitations stem from the small number of therapeutic agents that are specific with minimal side effects and capable of long term control of tumor growth. Lung cancer is considered one of the most deadly types of cancer for humans and is often diagnosed in a late incurable stage $[1,2]$. The vast majority of lung cancers are derived from epithelial cell carcinomas. The two main types are small cell lung cancer (SCLC) and non-small cell lung cancer (NSCLC), for which there are different treatment paradigms and expected survival outcomes. About $85 \%$ to $90 \%$ of lung cancers are NSCLCs. Three main subtypes of NSCLC exist differing in size, shape and chemical make-up [3]. Lung adenocarcinoma, an epithelial cancer of glandular origin, is the most prevalent of lung cancer diagnoses. Standard cytotoxic chemotherapy is effective in certain cases with majority of the available treatments offering only a limited survival benefit [4]. Metastasis is a multistep process and the main cause of mortality in lung cancer patients. The survival prognosis of lung cancer patients without treatment is very poor with a mortality rate of $98 \%$ [5]. To date, no effective methods for early diagnosis and treatment of lung cancer have been developed.

The interaction of biological cells with electromagnetic (EM) waves has been under investigation for several decades and non-thermal cytological effects of irradiation intensively studied [6]. In recent years there has been a growing interest in millimeter wave (MMW) irradiation as a possible treatment for cancer. MMW with frequencies within $30-300 \mathrm{GHz}$ cause biophysical effects without significantly increasing the temperature of the cells [7]. MMW penetration depth of biological tissue is a few millimeters only due to high absorption by water molecules. Experimental reports suggest MMW radiation likely affects information-carrying signals guiding internal processes in cells thereby affecting the whole organism. Illustratively, MMW irradiation within 40.5-51.8 GHz leads to biological activation of free nerve endings in the skin [8 - 10]. The central nervous system modulates neural activity resulting in the development of various biological effects, such as the release of endogenous opioids. The biochemical regulatory links of neuronal opioids of the local pulmonary opioid network affect human lung cancer cell proliferation [11, 12]. Further, endogenous opioids are reported to be involved in suppression of melanoma growth by MMWs [13].

Reversible morphological and ultrastructural alterations in erythromyeloid leukemia, melanoma and breast cancer cell lines by $53-78 \mathrm{GHz}$ MMW irradiation under $1 \mu \mathrm{W} / \mathrm{cm}^{2}[14-$ 16] demonstrated the anticancer treatment potential of this therapy. The effects were associated with a significant inhibition of cell proliferation correlated to structural membrane changes and energy metabolism modification of the exposed cells. In contrast, low power MMW exposure at $60.42 \mathrm{GHz}$ and $1 \mathrm{~mW} / \mathrm{cm}^{2}$ did not show any significant effects on the proliferation of multiple human cell lines [17]. These results suggest that the anti-cancer properties of MMW are directly dependent on irradiation parameters and/or the selective response of different cell types. For instance, an indirect influence of MMW exposure at $42.2 \mathrm{GHz}$ and $36.5 \mathrm{~mW} / \mathrm{cm}^{2}$ led to a decrease in tumor metastasis through activation of natural killer cells [18].

To date, the mechanism of MMW interaction with cells challenges research efforts. Most previous studies were done with discreet frequencies and/or in pulsed regimes of irradiation with very few of them involving a wide frequency spectrum. We reported cytotoxic effect of W-band (75-105 GHz) MMW corresponding to wavelengths $(\lambda)=4-2.73 \mathrm{~mm}$ based on morphological changes of H1299 human lung cancer cells [19]. The technique of the sweeping (frequency skipping) regime of MMW irradiation over 2 and 4 minutes exposure durations resulted in non-thermal accelerated cellular apoptosis and senescence of the treated cells only. The current study determines the exposure duration for clinical adaptation of the cytotoxic effect of MMW on cancerous cells without killing normal epithelial cells under the same 
conditions of optimized dose delivery. Specifically, we examined cellular mortality following W-band (75-105 GHz) MMW exposure on H1299 human lung cancer cells as compared to nontumorigenic MCF-10A human epithelial cells.

\section{Materials and Methods}

Media and cell cultures

H1299 Human lung cancer cells (also referred to as NCI-H1299 or CRL-5803) originally from ATCC were kindly provided by Prof. Uri Alon, Weizmann Institute of Science, Rehovot, Israel. H1299 cells were grown in RPMI medium (Biological Industries, Beth Ha'emek, Israel) supplemented with 10\% fetal bovine serum (FBS) (Biological Industries, Beth Ha'emek, Israel), penicillin (100 Units) and streptomycin $(100 \mu \mathrm{g} / \mathrm{ml}$ ) purchased from Sigma (St Louis, MO, USA) and $1 \mathrm{mM}$ glutamine/ml (Biological Industries, Beth Ha'emek, Israel).

Non-tumorigenic MCF-10A epithelial cells originally from ATCC were kindly provided by Prof. Yossi Shaul, Weizmann Institute of Science, Israel. MCF-10A cells were grown in Dulbecco's Modified Eagle's Medium (DMEM)/F12 containing 5\% horse serum, 1\% Penicillin/Streptomycin (all from Biological Industries, Beth Ha'emek, Israel), $20 \mathrm{ng} / \mathrm{ml}$ epidermal growth factor (EGF) (Peprotech, Rocky Hill, NJ, USA), and $0.5 \mathrm{mg} / \mathrm{ml}$ hydrocortisone, $100 \mathrm{ng} / \mathrm{ml}$ cholera toxin and $10 \mathrm{mg} / \mathrm{ml}$ Insulin (all from Sigma, St Louis, MO, USA).

Samples for irradiation were prepared from cells reaching $30 \%$ confluence. The number of plates prepared corresponded to the experimental schematics presented below. Control and test samples were examined every 2-3 days in order to prevent $100 \%$ confluence. Cells reaching $60 \%$ confluence were detached and transferred to new plates in order to avoid overcrowding. Transferred cells were seeded again at 30\% confluence for future growth and examination. These procedures were repeated over the 14-day observation period. Briefly, the cells were washed with phosphate buffered saline (PBS), detached with 0.25\% trypsin (all from Biological Industries, Israel) and seeded at a density of 200,000 H1299 cells per dish ( $35 \mathrm{~mm}$ diameter from Nunc, Thermo Scientific, USA) and 500,000 MCF-10A cells per dish. MCF-10A cells were used higher in number than that of H1299 cells due to their reduced proliferation in vitro in comparison. Further, since the therapy studied here is intended for endoscopic application with targeted localization at sites of cancerous lesions; non-specific radiation is expected to be avoided. Hence, this investigation analyzes the safety and clinical in situ applicability of this therapeutic modality. Cells were cultured in a humidified incubator corresponding to physiological conditions at $37^{\circ} \mathrm{C}$ and $5 \% \mathrm{CO}_{2}$ reaching $30 \%$ confluence on the day of experiment.

\section{Irradiation conditions}

Irradiation methods were maintained the same as previously reported [19] for stringency of analysis. Cells reaching 30\% confluence, as visually evaluated using a Nikon fluorescent microscope (Nikon Instruments Inc., Melville, NY, USA) were subjected to the irradiation protocol. Irradiation of the samples was performed in the sweeping regime [19]. Each run involved the frequency interval range 75-105 GHZ divided into 2000 - 2200 frequency steps. The duration of each single run was $200 \mathrm{~ms}$. Power density of irradiation was maintained constant at $0.2 \mathrm{~mW} / \mathrm{cm}^{2}\left(2 \mathrm{~W} / \mathrm{m}^{2}\right)$ in all experiments. Keeping the irradiation parameters same as previously reported [19], an average energy dose of 0.6, 1.2 and $3.0 \mathrm{~nJ}$ per H1299 cell corresponding to 2, 4 and 10 minute exposure regimes respectively were maintained.

Time-schedule and experimental conditions 
Cells were irradiated with MMW for 2, 4 or 10 minutes respectively on Day 1. Following exposure samples were incubated for up to 14 days under physiological conditions for experimental observations. On Day 1 (90 minutes after irradiation), Day 7 and Day 14, live cells were digitally imaged using a light microscope as mentioned above. To perform cytological assays cells were subsequently fixed in $4 \%$ formaldehyde for 30 minutes at $37^{\circ} \mathrm{C}$ for further analyses. For stringency of analysis and proper comparison of the experimental groups with a blank at every time point and all stages of the experiment; a reference group of cells served as an untreated (sham) control, undergoing the same procedures as the experimental groups but without irradiation. This served as control for comparisons of changes in morphological and physiological properties, and the cytological assays of the cells during experiments.

\section{Evaluation of cell mortality by DAPI staining}

Irradiated and control cells were stained with 4', 6-diamidino-2-phenylindole (DAPI) nuclear staining (Cell Apoptosis DAPI Detection Kit, GenScript, Piscataway, NJ, USA) for evaluation of cell death after MMW treatment. Cells were washed with $2 \mathrm{ml}$ of $1 \times \mathrm{PBS}$, fixed in $4 \%$ paraformaldehyde (Sigma, St. Louis, MO, USA) for 30 minutes at room temperature, and stained with $50 \mu \mathrm{g} / \mathrm{ml}$ of DAPI for 10 minutes at $4^{\circ} \mathrm{C}$. Cells were then washed twice with $1 \times$ PBS and analyzed under a fluorescent microscope as described below. 400 cells from each sample were counted and the percentage of dead cells calculated.

\section{Evaluation of cell senescence by $\beta$-Galactosidase ( $\beta$-Gal) assay}

To evaluate cell senescence after MMW treatment, irradiated and control cells were washed in 1xPBS, fixed in 3\% formaldehyde (Sigma, St. Louis, MO, USA) for 10 minutes at room temperature, then washed again and incubated at $37^{\circ} \mathrm{C}$ (without $\mathrm{CO}_{2}$ ) with fresh senescence associated (SA)- $\beta$-Gal stain solution containing $1 \mathrm{mg} / \mathrm{ml}$ 5-bromo-4-chloro-3indolyl P3-D-galactoside (X-Gal), $40 \mathrm{mM}$ citric acid/sodium phosphate ( $\mathrm{pH}$ 6.0), $5 \mathrm{mM}$ potassium ferrocyanide, $5 \mathrm{mM}$ potassium ferricyanide, $150 \mathrm{mM} \mathrm{NaCl}$ and $2 \mathrm{mM} \mathrm{MgCl}_{2}$ (all purchased from Sigma, Israel). Fixed cells were incubated with the staining solution prepared in a buffer ( $\mathrm{pH}$ 6.0) overnight at $37^{\circ} \mathrm{C}$. Cells, which stained blue, were considered positive for the activity of senescence-associated $\beta$-galactosidase and were counted. 400 cells from each sample were counted and the percentage of dead cells calculated in each respective experiment. Four independent experiments were performed for each assay.

\section{Microscopy observations and image processing}

Living and fixed cells were analyzed before and after the irradiation using the Nikon fluorescent microscope (Nikon Instruments Inc., Melville, NY, USA), with an objective x20 (which allowed sufficient cells for statistical analysis) and using an emission filter of 408-480 $\mathrm{nm}$ for DAPI staining. The pictures were captured using a digital color-chilled 3CCD camera (Hamamatsu, Bridgewater, NJ, USA) using the NIS elements microscope software program (Nikon Instruments Inc.). Produced images were analyzed by Image $1.48 \mathrm{~V}$ program (NIH and NIMH, USA). Image montages were processed on Photoshop CS6 software (Adobe Systems Inc., San Jose, CA, USA). Image processing included measurements of cell and nuclei areas; the ellipticity (circularity) of the nuclei; the correlation between the changes in the cells and their nuclei sizes; the number of pro-apoptotic and apoptotic cells; and the number of the senesced (aged) cells. 
Statistical analysis

Two-way independent analysis of variance (ANOVA) and Tukey-Kramer multiple comparison test were used for statistical analysis. $P$ values $<0.05$ were considered significant and $<0.001$ were considered extremely significant. To investigate the correlation between the distribution of the size of the cells and the size of the nuclei, the irradiated and sham cells were analyzed (counted) over the same number of subgroups (Table I). Pearson's correlation coefficient was calculated using the Excel (Microsoft Office Professional pus 2016) built-in package.

\section{Results}

Exposure duration-dependent effects of low power W-band (75 - 105 GHZ) MMW irradiation.

Our recent report [19] demonstrated W-band (75 - 105 GHZ) MMW irradiation for 2 and 4 minutes resulted in significant morphological changes indicative of Accelerated cellular apoptosis and senescence; however, with the genetically heterogenic lung cancer cell population still remaining viable. In this study we further increased the exposure duration to 10 minutes to compare the effects with the previous results. H1299 human lung cancer cells monolayer was irradiated by MMW for 2, 4 and 10 minutes in $35 \mathrm{~mm}$ polystyrene dishes (Figure 1). To evaluate the short-term effects of the irradiation, the cells were viewed under the microscope 1-2 hours after irradiation. To investigate the long-term effects of the irradiation, the cells were examined 7 and 14 days thereafter. To account for the heterogeneity of the nuclei population, as was previously shown [19], cells were classified into subgroups based on their morphological features and areas (Table I). 85\% of the control cells were at interphase and had almost circular or slightly oval-shaped nuclei. The distribution of the nuclei areas in the control groups were well correlated with the distribution of the cell sizes. 


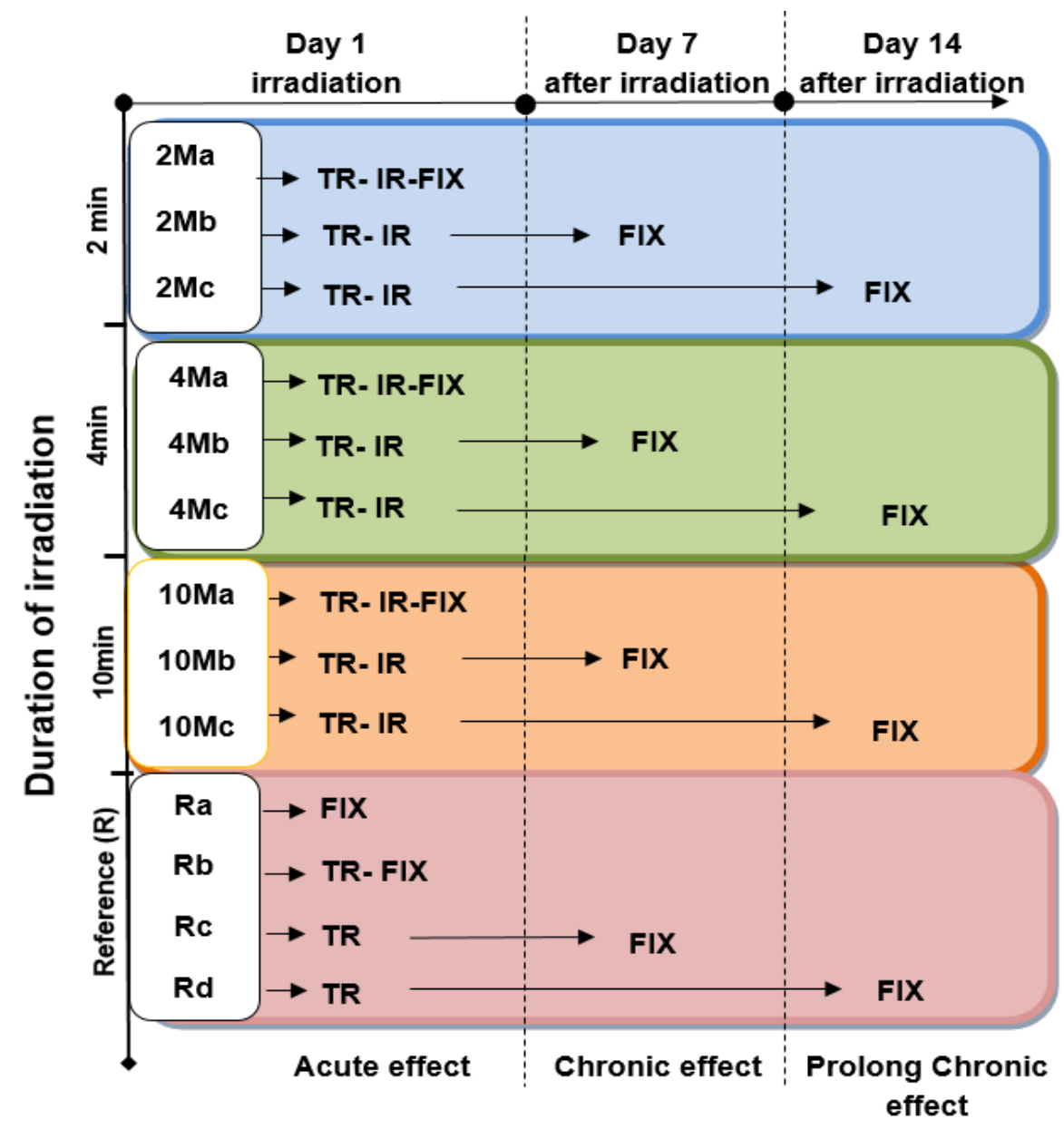

Figure 1. Experimental Schematic of H1299 human lung cancer cells monolayer irradiated by MMW for 2, 4 and 10 minutes in $35 \mathrm{~mm}$ dishes. The effects observed in the irradiated cells were compared to two types of control cells (see methods) - (i) the cells that remained in the incubator during the entire experiment, and (ii) the cells that were transferred to the irradiation setup and brought back together with the experimental groups but were not irradiated.

\begin{tabular}{|c|c|c|c|c|}
\hline $\begin{array}{c}\text { Number of } \\
\text { subgroup }\end{array}$ & $\begin{array}{c}\text { Cell area } \\
\left(\mu \mathrm{m}^{2}\right)\end{array}$ & Content of interval & $\begin{array}{c}\text { Form of the } \\
\text { nucleus }\end{array}$ & $\begin{array}{c}\% \text { of total number } \\
\text { in population }\end{array}$ \\
\hline $\mathbf{1 - 2}$ & $50-150$ & Interphase-G0-G1 & Round or oval & $30 \pm 3.7 \%$ \\
\hline $\mathbf{3 - 4}$ & $150-200$ & Interphase-G1-S & Round or oval & $46 \pm 5.1 \%$ \\
\hline $\mathbf{5 - 6}$ & $200-250$ & Interpase-S-G2 & Round or oval & $20 \pm 2.9 \%$ \\
\hline $\mathbf{6 - 7}$ & $200-300$ & Mitosis's & Dividing nuclei & $9 \pm 1.9 \%$ \\
\hline $\mathbf{8 - 9}$ & $300-400$ & "Monsters"/huge & Multi-lobed & $4 \pm 1.3 \%$ \\
\hline $\mathbf{1 0}$ & $500-600$ & Polyploid & Poly-nuclear & $1 \pm 0.67 \%$ \\
\hline
\end{tabular}

Table I: Distribution of H1299 cell population based on cell area, size and nuclear morphology. Subgroups formed are represented as percent of population.

Nuclear morphology of non-irradiated (control) H1299 cells. 
Concomitant with our recent report [19] observations in this study showed that most of the non-irradiated H1299 lung cancer cells present an average cellular size of $1500 \mu^{2}$ containing a single large round or oval nuclei, while 1-4 \% of the cells were 2.5-3.5 times larger $\left(5000 \mu^{2}\right)$ and characterized by multi-lobed and polyploidy cells with 3-11 nuclei per cell (Figure 2 A). Cells treated with MMW showed changes in nuclear morphology with the 4 minutes regime having a greater impact than the 2 minutes regime. The nuclei of cancer cells play a key role in the assessment of tumor malignancy through changes in genetic structure [20]. Cancer cells are characterized by a large nucleus with an irregular size and shape as well as prominent nucleoli. Morphological changes in their areas (in the adherent state) and the shapes of the cells may lead to changes in the cell's internal structures (like the nuclei) and can increase the chromosomal instability (ploidy) of cancer cells [21]. Effects of W-band MMW irradiation on nuclei number, shape and area were examined using DAPI (Figure 2A) and analyzed by observations under a fluorescent microscope.

A

Control

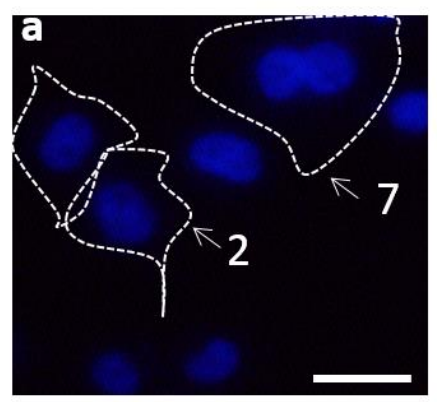

B

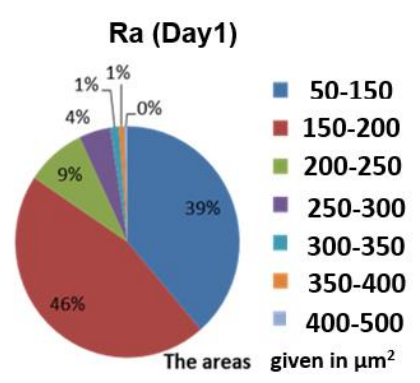

$2 \min$
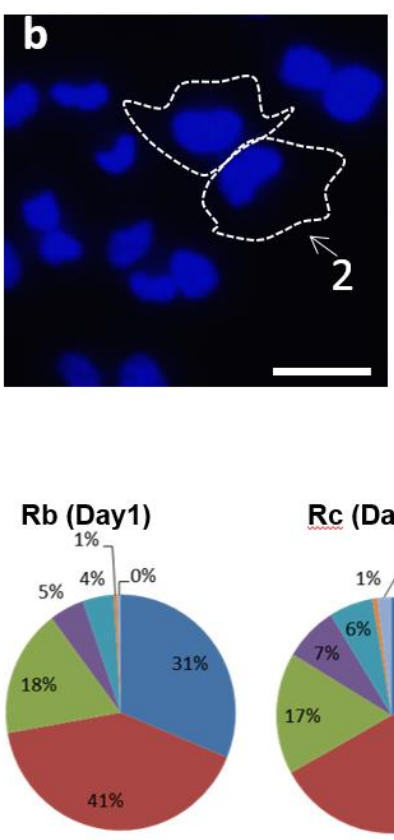

$4 \min$

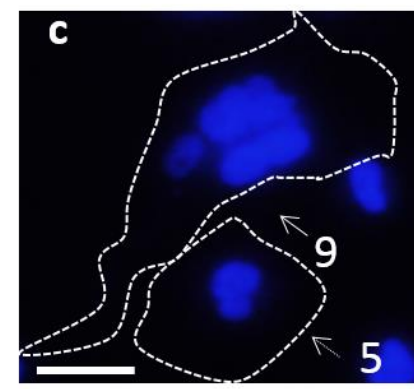

$\operatorname{Rc}($ Day7)

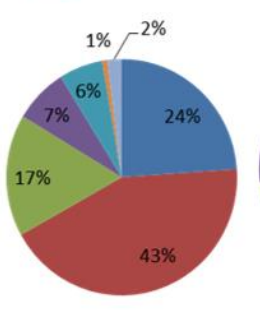

Figure 2. The distribution of the nuclei sizes and shapes in control and treated H1299 cells in response to MMW irradiation. A. Representative images of nuclei morphology before and after irradiation. (a) control cells' nuclei show circle or oval morphology; (b) kidney-like nuclei appeared over long-term incubation (7-14 days) after irradiation for 2 minutes; (c) multi-lobed and poly-nuclear cells appeared over long-term incubation (7-14 days) after irradiation for 4 minutes. Numbers indicate the subgroup classification as described in Table I. Scale bars correspond to $10 \mu \mathrm{m}$. B. Nuclei cell distribution by size in the cells. The areas indicated are given in $\mu \mathrm{m}^{2}$. Analysis of nuclei distribution in the control groups consisted of four dishes (Ra-d). 400-475 cells were measured in each group for each day of observation. Each experiment involved four repeats.

The nuclear sizes of the cells in normal growth conditions were measured, over 14 days of the experimental observation period (Fig. 2Ba), after processing them through the same conditions as the irradiated cells except without the MMW treatment procedure itself. The average areas of control cell nuclei ranged from $100-250 \mu \mathrm{m}^{2}$ (subgroups $1-5$ ), 9\% of the cells contained nuclei under division (subgroup 6-7) with an area 200-300 $\mu^{2}$ and up to $4 \%$ of the cells (subgroups 8-10) contained a multi-lobular, irregular nuclei or cells that contained 3-11 
nuclei per cells, with area ranging $300-600 \mu \mathrm{m}^{2}$. No significant changes in area distribution were observed over 7 days of proliferation, while the population of the cells with larger nuclei (subgroups 6-10) increased slightly over 14 days of proliferation due to natural senescence. These physiological trends occurring naturally in the cells were considered normal conditions of division and taken into account during statistical analyses of the irradiation experiments performed subsequently.

H1299 cell nucleus shapes and sizes change in response to MMW irradiation.

To examine whether the observed effects were transient (reversible) or irreversible (stable), the nuclei sizes and shapes were monitored over 7 - 14 days after irradiation. MMW irradiation for 2, 4, and/or 10 minutes duration led to changes in nuclear size in irradiated groups (Figure $3 \mathrm{~A}$ and B). Samples irradiated for 2 minutes showed a relative $100 \%$ increase in the nuclear sizes of cells from subgroups 6-7 (cell division active) only as compared to untreated (sham) cells (Table II). Under the 2 minutes regime, cells from the other subgroups were not so dramatically affected. By delivering higher energy dosage more prominent effects on nuclear sizes were seen under the 4 and 10 minutes exposure regimes. MMW irradiation were seen to elicit two major responses in the treated cells indicative of apoptosis and senescence respectively as previously reported [19]. One group of cells (from subgroups 1-4) mostly reduced their nuclear sizes (by 25\%-200\%) while another set (from subgroups 4-10) increased their nuclear sizes (by 30\%-300\%) (Figure 3B and Table II) under the 4 and 10 minutes exposure regimes. The cells irradiated for 10 minutes didn't survive after a few days in culture, demonstrating that the effects of the treatment were irreversible on cell viability. Thus, experimental observations for further investigations were possible only on the groups that were treated with shorter durations of irradiation. The changes observed on cell and nuclear morphology associated with shorter and longer exposure durations; clearly confirm the strong and specific effect of MMW on lung cancer cell properties and viability. This experiment also demonstrates that the cells from subgroups 6-7 (cell division active) were the ones most affected indicating the effectiveness of MMW treatment in inhibiting metastasis.

A

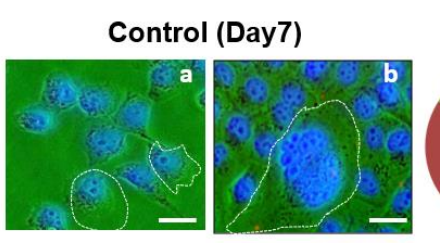

$4 \min ($ Day7)

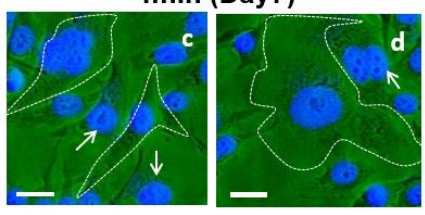

$4 \min ($ Day14)

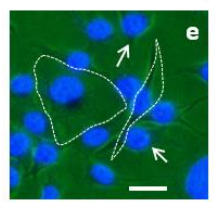

\section{B}
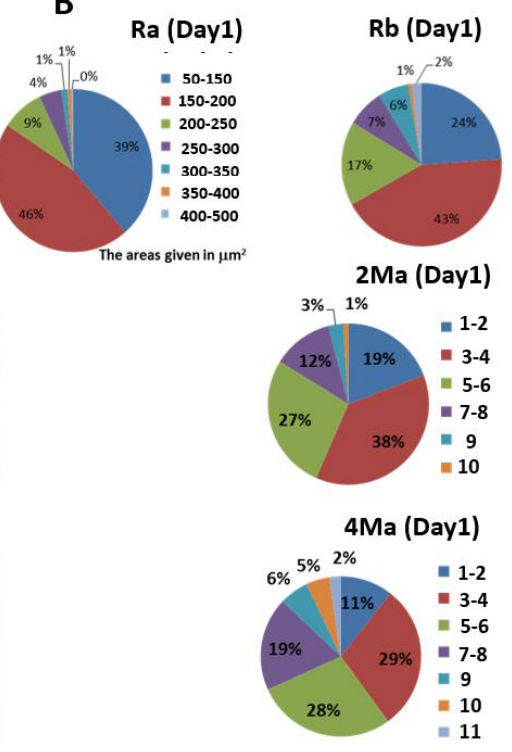

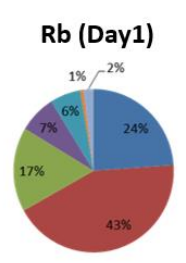

\section{1)}
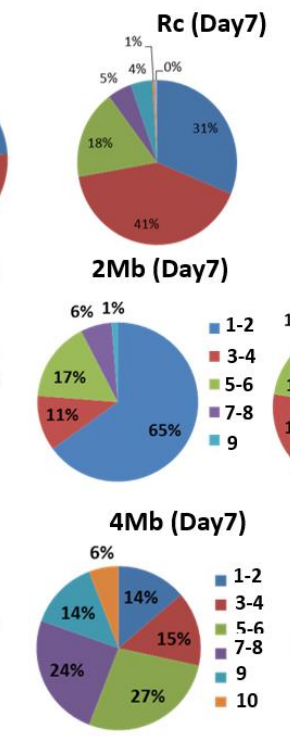
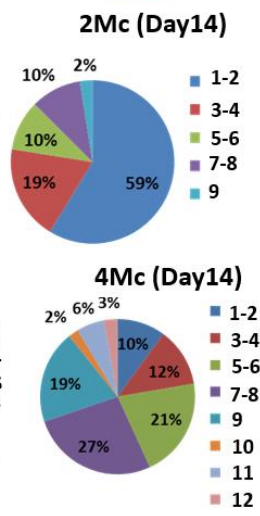

Figure 3. The distribution of the nuclei sizes and shapes in control and treated H1299 cells populations in response to MMW irradiation. A. Representative images of nuclei morphology after irradiation. (a) control cells nuclei show circle or oval morphology; (b) cells with enlarged nuclear morphology under 
the 2 minutes irradiation regime corresponding to subgroups 1-2 from Table II observed over long-term incubation of 7-14 days after MMW treatment; (c) \& (e) cells with altered nuclear morphology under the 4 minutes irradiation regime observed on the day of experiment (Day 1). (d) \& (f) cells with enlarged nuclear morphology under the 4 minutes irradiation regime corresponding to subgroups 4-10 from Table II observed over long-term incubation of 7-14 days after MMW treatment. Arrows indicate altered nuclei as compared to control. Scale bars correspond to $10 \mu \mathrm{m}$. B. Distribution of nuclei by size in lung cancer cells. (A) Nuclei distribution by size of reference groups. The areas indicated are given in $\mu \mathrm{m}^{2}$. Ra-d correspond to control groups of four separate dishes ( $\mathrm{Ra}, \mathrm{Rb}, \mathrm{Rc}$ and $\mathrm{Rd}$ ). The group Ra was imaged and fixed before the experiment. The control groups $\mathrm{Rb}$, Rc and $\mathrm{Rd}$ accompanied all the MMW treated samples undergoing the same procedure as the experimental groups except the irradiation; for proper comparison of the experimental groups with the control ones at all stages of the experiment since the morphological and physiological properties of the cells change during physiological incubation due to normal proliferation. During the whole experiment the average size of nuclei measured increased. 2Ma-c correspond to 2 minutes exposure and $4 \mathrm{Ma}-\mathrm{c}$ correspond to 4 minutes exposure respectively. The areas of nuclei increase over time from Day 1 to Day 14 . The groups $2 \mathrm{~mA}$ and $4 \mathrm{Ma}$ represent the acute effect of MMW irradiation on Day 1 of MMW treatment. The groups $2 \mathbf{M b}-\mathbf{c}$ and $4 \mathbf{M b}-\mathbf{c}$ represent the chronic effects of MMW irradiation observed over 7-14 days after MMW treatment. The values in the legends denote ratios of measured areas of the experimental groups to the average area $\left(160 \mathrm{um}^{2}\right)$ of the control groups on corresponding days. The percentage given in pies represent the actual percent of the indicated subgroup within whole population. The basic effect of the irradiation for both exposure durations show that nuclei grow in size, and 4 minutes exposure leads to remarkable increase in the number of multinuclear cells. 400-550 cells were measured in each group per experiment. Each experiment involved four repeats.

\begin{tabular}{|c|c|c|c|c|c|c|c|}
\hline Subintervals & $\begin{array}{c}\mathbf{2 M a} \\
\text { (Day1) }\end{array}$ & $\begin{array}{c}\mathbf{2 M b} \\
\text { (Day7) }\end{array}$ & $\begin{array}{c}\mathbf{2 M c} \\
\text { (Day14) }\end{array}$ & $\begin{array}{c}\mathbf{4 M a} \\
\text { (Day1) }\end{array}$ & $\begin{array}{c}\text { 4Mb } \\
\text { (Day7) }\end{array}$ & $\begin{array}{c}\text { 4Mc } \\
\text { (Day14) }\end{array}$ & $\begin{array}{c}\text { 10Ma } \\
\text { (Day1) }\end{array}$ \\
\hline $1-2$ & -30 & +150 & +125 & -200 & -30 & -150 & -170 \\
\hline $3-4$ & $\approx$ & -300 & -25 & -25 & -200 & -100 & -120 \\
\hline $4-5$ & +30 & $\approx$ & -150 & +30 & +30 & $\approx$ & -5 \\
\hline $6-7$ & +100 & $\approx$ & -30 & +300 & +300 & +30 & +100 \\
\hline $8-10$ & $<5$ & $<5$ & $<5$ & +120 & +20 & +200 & +250 \\
\hline
\end{tabular}

Table II: Changes in nuclei size distribution compared with control groups (\%). Subintervals denote the subgroups of cells with different sized nuclei as described in Figure 3. The values represent the percent change of irradiated nuclei size relative to control (\%). Red represents a decrease and green represents an increase.

Under the short-term observation period (Day 1, 90 minutes following irradiation) the effects resulting from 2 minutes of irradiation were less profound as compared to 4 and 10 minutes exposures. The 4 minutes irradiation regime delivering a higher dose of energy showed that the major effect of MMW treatment was reduction in nuclear size distribution in response to the irradiation reminiscent of accelerated apoptosis [19] and mortality. However, the small population of the large cells with multi-lobular nuclei increased their sizes 3 folds as compared to control. This may indicate that nuclei lose their ability to maintain their shape and/or that new subgroups of cells with different properties appear and transition into proapoptosis. Further, over 14 days of experimental observation, nuclei morphology prominently changed in response to the irradiation. The irradiated cells that contained only one nucleus were changed from oval to kidney-like for both 2- and 4-minute exposure times (Figure 3A), likely due to changes in DNA condensation via adverse regulation and the appearance of small pro-apoptotic subgroups in the cell populations. These results demonstrate that W-band (75 $105 \mathrm{GHz}$ ) MMW has an effect on cell sizes as well as the cell nuclei in a dose dependent manner. 
The size of a cell and its nucleus are interlinked [22] and biologically regulated. The ratio between nuclear and cytoplasmic volumes, also termed as the karyoplasmic ratio $[\mathrm{N} / \mathrm{C}]$ ) is crucial to cellular integrity [23]. The effect of irradiation on the $\mathrm{N} / \mathrm{C}$ ratio was therefore investigated with and without MMW treatment. High variability of the N/C ratio was observed by qualitative microscopic analysis comparing the nuclei and cells sizes and quantitative measurements of their sizes (Table III). N/C ratio was $32-36 \%$ in the control group on Day 1 and remained consistent within this range over the observation period of 7-14 days of physiological incubation. In response to 2 minutes irradiation on Day 1, the N/C ratio shifted to $42 \%$ in the cell populations and decreased to $28-29 \%$ over $7-14$ days of experimental observation following MMW treatment. In response to 4 minutes irradiation on Day 1, the N/C ratio shifted to $52 \%$ in the cell populations and reached $57-66 \%$ over 7 - 14 days of experimental observation following MMW treatment. This indicates that increase in energy dosage on the irradiated H1299 cells reduced their ability to repair themselves. The threshold limit of this ability was crossed in response to 10 minutes irradiation shifting the N/C ratio to $78 \%$ in the cell populations on Day 1 and all the cells dying a couple of days later. Interestingly, the increase in N/C ratio did not arise only due to an increase in nuclear size but also corresponded with a reduction in size of the cell cytoplasm (Table III), indicative of cell shrinkage and the dose dependent accelerated apoptosis cell mortality effect reported previously [19] in response to MMW treatment. Thus, a de-correlation effect of irradiation on Day 7 and 14 after MMW treatment is observed. Illustratively, under the 4 minutes exposure regime irradiated cells presented an increase in N/C ratio to 52-66\% over the observation period of 7-14 days following MMW treatment (Table III). Long-term effects observed on Days 7 and 14 were accompanied not only by changes in the cell and nuclei sizes but also by changes in their geometric relationship. Further, the exposure time had a distinct effect on the N/C ratio.

\begin{tabular}{|l|c|c|c|}
\hline \multicolumn{1}{|c|}{ Group } & Cell size & $\begin{array}{c}\text { Nuclear } \\
\text { size }\end{array}$ & $\begin{array}{c}\text { Nuclei/Cells } \\
\text { (\%) }\end{array}$ \\
\hline $\begin{array}{l}\text { Ra (Day 1, } \\
\text { not trans) }\end{array}$ & NC & NC & $32 \pm 5.4$ \\
\hline $\begin{array}{l}\text { Rb (Day 1, } \\
\text { trans) }\end{array}$ & NC & NC & $36 \pm 6.3$ \\
\hline Rc (Day7) & NC & NC & $34 \pm 8.1$ \\
\hline Rd (Day14) & NC & NC & $33 \pm 5.7$ \\
\hline 2Ma (Day1) & $\downarrow$ & $\uparrow$ & $42 \pm 3.9$ \\
\hline 2Mb (Day7) & $\uparrow$ & $\downarrow$ & $28 \pm 5.0$ \\
\hline 2Mc (Day14) & $\uparrow$ & $\downarrow$ & $29 \pm 2.6$ \\
\hline 4Ma (Day1) & $\downarrow$ & $\uparrow$ & $52 \pm 3.3$ \\
\hline 4Mb (Day7) & $\downarrow$ & $\uparrow$ & $57 \pm 6.5$ \\
\hline 4Mc (Day14) & $\downarrow$ & $\uparrow$ & $66 \pm 7.6$ \\
\hline 10Ma (Day 1) & $\downarrow$ & $\uparrow$ & $78 \pm 5.4$ \\
\hline
\end{tabular}

Table III: Ratio of average areas - Nuclei/Cells. Averages of the cell and nuclei sizes of each subgroup were used for $\mathrm{N} / \mathrm{C}$ ration calculation.

The relationship between the size of the cells and their nuclei with the observed changes were examined for the cell population subgroups using Pearson's correlation coefficients (Table IV). The distribution of cells and nuclei sizes in the control groups showed a strong positive 
correlation ( $c=0.85$ - 0.91). Cells exposed for 2 minutes showed a weak positive correlation (c $=0.04-0.35)$ while the cells exposed for 4 and 10 minutes showed a negative correlation $(\mathrm{c}=(-$ $0.11)-(-0.41)$ and $(-0.35))$ i.e. an inverse correlation between the distributions. The N/C decorrelation effect as observed for the irradiated cells was apparently caused by MMW irradiation.

\begin{tabular}{|c|c|c|c|}
\hline \multicolumn{4}{|c|}{ Table IV: Decorrelation between cells' and nuclei } \\
distributions. \\
\hline Group & Day 1 & Day 7 & Day 14 \\
\hline Control & 0.85 & 0.91 & 0.90 \\
\hline 2 min & 0.35 & 0.04 & 0.17 \\
\hline 4 min & -0.11 & -0.2 & -0.41 \\
\hline $10 \mathrm{~min}$ & -0.35 & - & - \\
\hline
\end{tabular}

Table IV: Quantitative analysis of karyoplasmic (nuclei/ cell) ratios. Correlation coefficients calculated by Pearson's formula for cells and nuclei distributions. 2 minutes irradiation reduced the nuclei size slightly as compared to cellular size, while 4 minutes irradiation increased the nuclei size. The observations indicate different durations of exposure effects cell morphology differently. The control groups show strong positive correlation while the irradiated groups reveal strong decorrelation (weak positive for 2 minutes exposure and strong negative for 4 and 10 minutes exposure). Cells under 10 minutes exposure died before reaching Day 7 and 14 of the observation period following MMW treatment. Indicated values represent the mean of three independent experiments.

This experiment suggests that the desired effect of targeted mortality of H1299 cells in response to MMW treatment is directly dependent on the dosage of energy within the applied power density. Specifically, it indicates that the threshold effect is observed when the N/C ratio crosses beyond $70 \%$. The subsequent experiments investigate this surmise using cytological assays to determine the efficacy of the different treatment regimes in terms of exposure durations.

Short-term and long-term mortality and senescence effects of MMW irradiation on H1299 cancer cells

To examine whether MMW irradiation affects cell death and senescence, DAPI staining and $\beta$-galactosidase colorimetric assay were performed (Figure $5 \mathrm{~A}$ and $6 \mathrm{~A}$ ) and the results summarized in Tables V and VI. Following MMW irradiation three different cell subgroups were observed: dead cells, senescent cells and proliferating cells. Under the 2 minutes irradiation regime on the day of the irradiation (Day 1), approximately $14 \%$ of the cells died after irradiation compared to only $4 \%$ of control cells (Figure 5B and Table V). Under this exposure regime, dead cells further increased to almost $30 \%$ in the population over 7 days of post irradiation incubation and was reduced to $3.4 \%$ by day 14 . Cells under 4 minutes irradiation showed about $14 \%$ mortality on Day 1, which decreased to $8 \%$ on Day 7 and reached around $10 \%$ by Day 14 . Cells exposed to 10 minutes irradiation showed mortality of almost $47 \%$ of the cell population on Day 1 and were completely dead before reaching days 7 and 14 of the observation period. The results suggest that under the 2 minutes irradiation regime majority of the cell population avoid the immediate cytotoxic effect as energy dose is lower than the 4 minutes exposure regime but develop pro-apoptotic fates gradually. These cells die out over the next 7 days of observation beyond which the cells that remain in the petri dish give rise to progeny devoid of any MMW treated effects on Day 14. Hence, the low mortality rate on Day 14 under the 2 minutes irradiation regime. In the case of 4 minutes 
exposure, mortality on Day 1 is much higher due to higher energy dosage. This allows only a small population of cells to continue proliferating into the subsequent 7-14 days period of observation. And hence a higher mortality on Day 14 for cells under the 4 minutes regime as compared to those under the 2 minutes duration. This conjecture is further supported by the observation of increased mortality associated with increasing the duration of exposure to 4 and 10 minutes which translates into higher dose delivery.

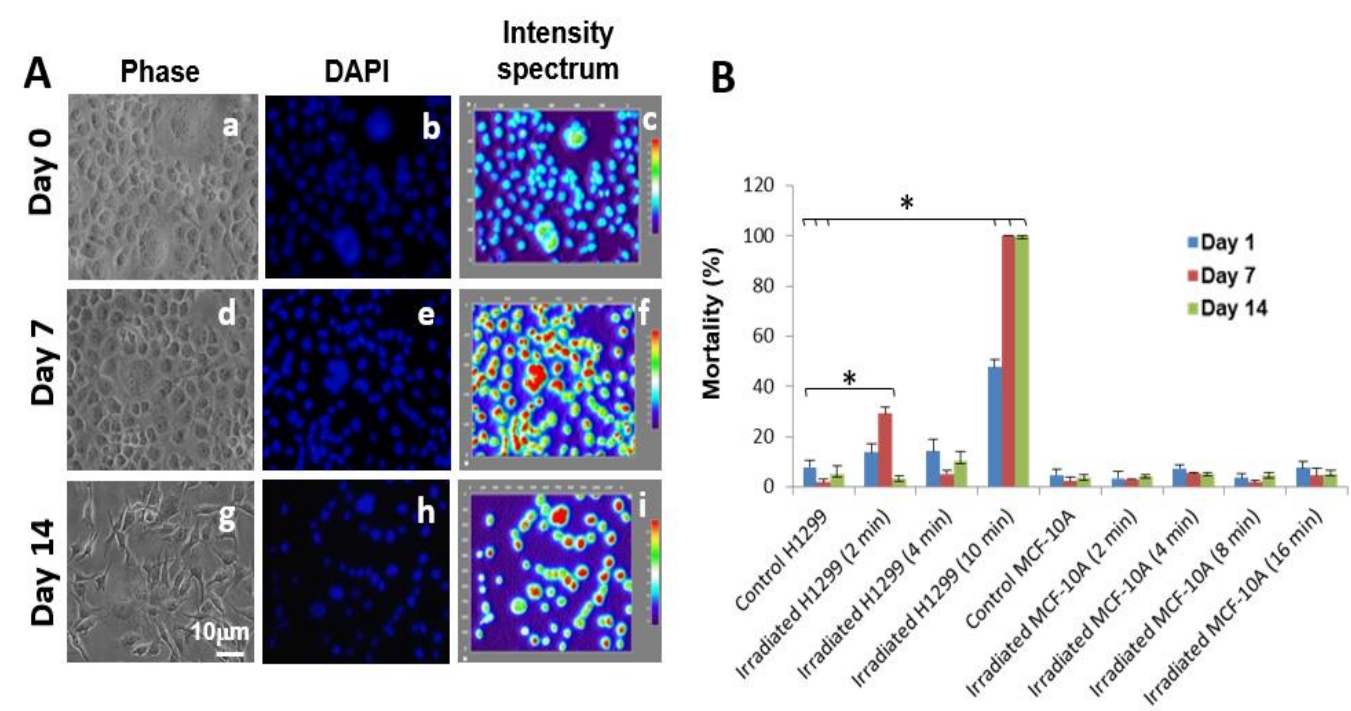

Figure 5. (A) Mortality effect following W-band (75 - $105 \mathrm{GHz}$ ) MMW treatment on H1299 and MCF-10A cell lines. Scale bars correspond to $10 \mu \mathrm{m}$. (B) 400- 550 cells were counted for each group. Each experiment was repeated four times. * indicates $\mathrm{p}$-value $<0.01$

\begin{tabular}{|c|c|c|c|c|c|}
\hline \multicolumn{2}{|c|}{ Cell Type } & \multirow{2}{*}{\begin{tabular}{c} 
Exposure \\
Time \\
\cline { 4 - 6 }
\end{tabular}} & \multicolumn{3}{|c|}{$\begin{array}{c}\text { Mortality (\%) } \\
\text { in observed days }\end{array}$} \\
\cline { 3 - 6 } & & & Day 1 & Day 7 & Day 14 \\
\hline \multirow{3}{*}{ H1299 } & Control & 0 & $3.9 \pm 2.7$ & $1.9 \pm 3.3$ & $3.1 \pm 0.88$ \\
\cline { 3 - 6 } & \multirow{3}{*}{ Irradiated } & 2 & $13.9 \pm 1.2$ & $29.3 \pm 2.6$ & $3.4 \pm 1.4$ \\
\cline { 3 - 6 } & & 4 & $14.3 \pm 2.9$ & $8.3 \pm 2.0$ & $10.3 \pm 3.3$ \\
\cline { 3 - 6 } & & 10 & $46.8 \pm 4.3$ & Cell died & Cell died \\
\hline \multirow{4}{*}{ MCF-10A } & Control & 0 & $4.9 \pm 1.7$ & $2.5 \pm 1.8$ & $3.7 \pm 1.6$ \\
\cline { 3 - 6 } & \multirow{3}{*}{ Irradiated } & 2 & $3.6 \pm 2.0$ & $3.0 \pm 1.3$ & $4.4 \pm 1.9$ \\
\cline { 3 - 6 } & & 4 & $7.5 \pm 3.1$ & $5.5 \pm 2.1$ & $5.3 \pm 2.5$ \\
\cline { 3 - 6 } & & 8 & $3.7 \pm 1.5$ & $1.9 \pm 0.9$ & $4.7 \pm 1.7$ \\
\cline { 3 - 6 } & 16 & $7.6 \pm 2.6$ & $4.6 \pm 1.4$ & $5.3 \pm 2.2$ \\
\hline
\end{tabular}

Table V: Summary of the mortality effect following W-band (75 - $105 \mathrm{GHz})$ MMW treatment on H1299 and MCF-10A cell lines.

Senescence occurs in cells during the pro-apoptotic stage and excludes the possibility of division (mitosis). In a normal H1299 cell population, generally about 1-3\% of the cells are dead and/or in senescence (ref. Table I). Under the 2 minutes irradiation regime on the day of the irradiation (Day 1), approximately $34 \%$ of the cells showed senescence after irradiation compared to only $18.6 \%$ of control cells (Figures $6 \mathrm{~B}$ and Table VI). Under this exposure regime, cells undergoing senescence reduced to $19 \%$ in the population over 7 days of post irradiation incubation and was increased to $24.6 \%$ by day 14 . Cells under 4 minutes irradiation showed approximately $37 \%$ senescence on Day 1, which decreased to $28.6 \%$ on Day 7 and reached around $66 \%$ by Day 14 . Cells exposed to 10 minutes irradiation showed almost $70 \%$ senescence of the cell population on Day 1 and were completely dead before reaching days 7 and 14 of the observation period. 
The long-term effects on H1299 cell death and senescence observed after the 4 minutes exposure were more profound than the effects observed for the 2 minutes regime (ref. Figure $5 \mathrm{~B}$ and $6 \mathrm{~B}$ ). The results indicate that 4 minutes of irradiation delivering higher energy dosage affects the heterogeneous population of lung cancer cells and most cells that do not die become a part of the senescent cell populations. Moreover, as mentioned above, irradiation for 10 minutes led to the complete cell death of the entire population after two days following MMW treatment.

Mortality and senescence effects of MMW irradiation observed in H1299 cancer cells does not affect MCF-10A non-tumorigenic cells.

To investigate whether the same irradiation procedures affect healthy cells, nontumorigenic MCF-10A cells, an immortalized and non-transformed mammary epithelial cell line [24] were exposed to $\mathrm{W}$-band $(75-105 \mathrm{GHz}) \mathrm{MMW}$ under the same power densities. These cells have a near diploid karyotype and are dependent on exogenous growth factors for proliferation. They also lack the ability to form tumors in nude mice. DAPI staining and $\beta$ galactosidase colorimetric assay were used to examine the effects of MMW irradiation on mortality and senescence of MCF-10A cells. The cells were irradiated for 2, 4, 8 and 16 minutes (Figure 5B and 6B). The cells survived for 14 days following MMW exposure under the abovementioned irradiation parameters and did not show mortality or senescence effects as observed for the H1299 cells. Under the 2 minutes irradiation regime on the day of the irradiation (Day 1), approximately $3.6 \%$ of the cells died after irradiation comparable to about $5 \%$ of control cells (Figure 5B and Table V). Under this exposure regime, dead cells remained within 3-4.4\% in the population over 7-14 days of post irradiation incubation after MMW treatment. Cells under 4 minutes irradiation showed $7.5 \%$ mortality on Day 1 and remained around $5 \%$ in the population over 7-14 days of post irradiation incubation after MMW treatment. Cells exposed to 8 minutes irradiation showed mortality of almost $4 \%$ of the cell population on Day 1 and remained within $2-4.7 \%$ in the population over 7-14 days of post irradiation incubation after MMW treatment. Cells exposed to 16 minutes irradiation showed mortality of $7.6 \%$ of the cell population on Day 1 and remained within $4.6-5 \%$ in the population over 7-14 days of post irradiation incubation after MMW treatment. It should be noted that these cells remained unaffected even after prolonged exposures of up to 16 minutes.

A

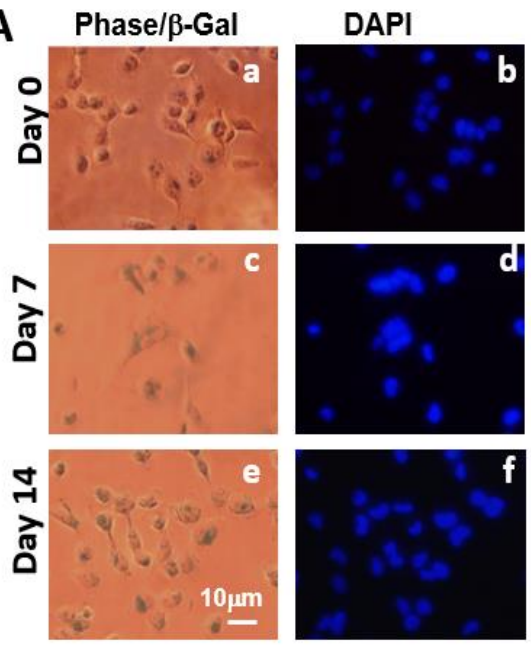

B

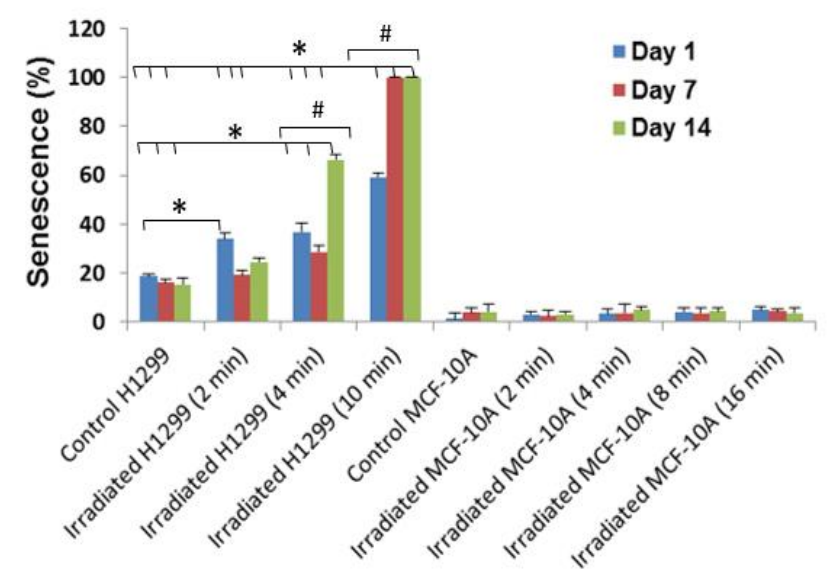


Figure 6. (A) Senescence effect following W-band (75 - $105 \mathrm{GHz}$ ) MMW treatment on H1299 and MCF10A cell lines. Scale bars correspond to $10 \mu \mathrm{m}$. (B) 400-550 cells were counted for each group. Each experiment was repeated four times. ${ }^{*}$ indicates $\mathrm{p}$-value $<0.05$ and 0.01

\begin{tabular}{|c|c|c|c|c|c|}
\hline \multicolumn{2}{|c|}{ Cell Type } & \multirow{2}{*}{\begin{tabular}{c} 
Exposure \\
Time \\
\cline { 3 - 6 }
\end{tabular}} & \multicolumn{3}{|c|}{$\begin{array}{c}\text { Senescence } \\
\text { in observed days }\end{array}$} \\
\cline { 3 - 6 } & $(\mathrm{min})$ & Day 1 & Day 7 & Day 14 \\
\hline \multirow{3}{*}{ H1299 } & Control & 0 & $18.6 \pm 2.8$ & $16.2 \pm 1.6$ & $15.4 \pm 15$ \\
\cline { 3 - 6 } & & 2 & $34.0 \pm 3.0$ & $19.3 \pm 2.5$ & $24.6 \pm 1.3$ \\
\hline \multirow{4}{*}{ Irradiated } & & 4 & $36.9 \pm 4.1$ & $28.6 \pm 3.3$ & $66.3 \pm 2.7$ \\
\cline { 3 - 6 } & & 10 & $69.1 \pm 3.7$ & Cell died & Cell died \\
\cline { 3 - 6 } & Control & 0 & $1.4 \pm 0.9$ & $4 \pm 1.2$ & $4.3 \pm 1.8$ \\
\cline { 3 - 6 } & & 2 & $3.1 \pm 1.4$ & $2.5 \pm 0.7$ & $3.1 \pm 1.1$ \\
\cline { 3 - 6 } & & 4 & $3.4 \pm 2.2$ & $3.8 \pm 0.6$ & $5.0 \pm 2.1$ \\
\cline { 3 - 6 } & \multirow{3}{*}{ Irradiated } & 8 & $4.2 \pm 1.9$ & $3.7 \pm 1.1$ & $4.4 \pm 1.9$ \\
\cline { 3 - 6 } & & 16 & $5.0 \pm 2.3$ & $4.4 \pm 1.5$ & $3.7 \pm 0.8$ \\
\hline
\end{tabular}

Table VI: Summary of the senescence effect following W-band (75 - $105 \mathrm{GHz})$ MMW treatment on H1299 and MCF-10A cell lines.

Samples treated under the 2 minutes irradiation regime showed about 3\% senescence on the day of the irradiation (Day 1), which was slightly higher than the $1.4 \%$ of control cells (Figure 6B and Table VI). Under this exposure regime, senescent cells remained within 2.5-3\% in the population over $7-14$ days of post irradiation incubation after MMW treatment. Cells under 4 minutes irradiation showed 3.4\% mortality on Day 1 and remained around 3.8-5\% in the population over $7-14$ days of post irradiation incubation after MMW treatment. Cells exposed to 8 minutes irradiation showed senescence of about $4 \%$ of the cell population on Day 1 and remained within $3.7-4.4 \%$ in the population over $7-14$ days of post irradiation incubation after MMW treatment. Cells exposed to 16 minutes irradiation showed senescence of $5 \%$ of the cell population on Day 1 and remained within $4.4-3.7 \%$ in the population over $7-14$ days of post irradiation incubation after MMW treatment.

\section{Discussion}

The aim of the present study was to investigate the effect of low-intensity W-band (75$105 \mathrm{GHz}$ ) MMW irradiation on heterogeneous, aggressive, drug-resistant human H1299 lung cancer cells as compared to normal non-tumorigenic MCF-10A epithelial cells. Each cell sample was irradiated once for 2, 4 or 10 minutes and the change in cell morphology and viability was followed for up to 14 days. Irradiation of H1299 cells for 2 and 4 minutes led to observable changes in the cell and nucleus morphology, significantly increasing cell mortality and senescence over 7 - 14 days following MMW exposure. The effects were found to be specific and irreversible in the irradiated H1299 cells and were not observed in the control group of non-irradiated (control) cells during the 14 days of experimental observation. Although cell death and senescence both increased in H1299 cell populations during the experiment, their temporal kinetics were different. Cell mortality peaked 7 days after irradiation, while senescence peaked on Day 14 for 2 and 4 minutes of irradiations. Cell deaths occurred likely due to the inability of MMW exposed cells to repair themselves after irradiation, while some damaged cells survived and formed an aged cell population. Such senescent cells are reported to survive for a long time and arrest the apoptotic stimuli of the physiological cycle [25]. These two different effects possibly originate from activation and/or inhibition of different physiological mechanisms involving tumor development [26]. 
The effects of irradiation on cell death and senescence were confirmed by observations of non-thermal morphological changes previously reported [19]. Changes in cell shapes occurred parallel to the changes in cell size following MMW exposure. Decrease in the cell size was in accordance with the increase in their circularity and cell diameter and vice versa. In the current study, changes in nuclear shape and size were also observed after MMW treatment. Such physical changes indicate the formation of two functionally distinct cell groups: proapoptotic and senescent. The pro-apoptotic cells present decreased cell and nuclei sizes with increased circularity, in addition to fragmented nuclei indicating internal damage. The prosenescence cell phenotype shows an increase in both cell and nuclei sizes. They exhibit flattened forms containing "puffed" nuclei with kidney-like shapes [26]. A small proportion of the H1299 cell population comprised mitotic and huge polyploid cells whose numbers increased following irradiation, possibly due to nuclear changes. Reports suggest their formation arising from perturbations of the molecular mechanisms that control replication and cell division [27, 28]. In H1299 cells they were represented by two phenotypes: one with a large single nucleus and the other - with multinucleated cells (MNC) containing up to 11 nuclei. These cells were positively stained with the $\beta$-galactosidase (SA- $\beta-\mathrm{Gal}$ ) senescence marker and had an ability to divide although the cytoplasm exhibited no division. Therefore, these cells are suspected to have been resistant to 2 and/or 4 minutes irradiation (which delivered lower energy dosage as compared to the terminal cytotoxic effect of 10 minutes regime); and likely to be the source of the cell population that survived over 7 - 14 days. Studies similarly report that polyploidy cells were more resistant to chemotherapeutic agents than mononuclear cells (MNCs) [28]. Further, MNCs undergo asymmetric division (producing mononuclear cells) and self-renewal in vitro and in vivo; with a single cell capable of generating orthotropic subcutaneous tumors (composed mainly of mononuclear cells) giving rise to spontaneous lung metastases in nude mice. However, the 10 minutes exposure regime successfully terminated these multinuclear as well as the mononuclear H1299 cells. Our results indicate that this selective irradiation therapy can affect the viability of heterogeneous H1299 lung cancer cells in vitro.

MMW irradiation is reported to interact with cell compartments such as membranes, cytoskeletons, chromosomes and nuclei [29-32]. Biological membranes are suggested to be the main target of MMW irradiation within $1-80 \mathrm{GHz}[33,34] .50 \mathrm{GHz}$ MMW exposure at 10 $\mathrm{mW} / \mathrm{cm}^{2}$ for 2 minutes resulted in a transient membrane permeability change in immortalized epithelial H1299 cells [35]. We report accelerated cellular mortality and senescence of H1299 cells observed over a period of 7-4 days after W-band (75-105 GHz) MMW exposure at 0.2 $\mathrm{mW} / \mathrm{cm}^{2}$. The 2 minutes dose induced a slightly increased mortality effect as compared to controls, the 4 minutes dose gave enhanced mortality and the 10 minutes exposure resulted in complete mortality of irradiated cell populations. Molecular resonance with MMW induce reversible externalization of phosphatidylserine molecules in human keratinocyte and murine melanoma cells exposed in vitro likely affecting the functional state of phospholipids in biomembranes without detectable membrane damage [36]. Thus, energy dose and frequency determine the extent of biophysical modulation occurring in cells in response MMW exposure. Further, the observations suggest that duration of exposure can be appropriately tuned to elicit specific resonances of structures with corresponding dimensions within the cellular environment. As an application of Frohlich resonance this results in a cascade of events causing the observed changes to activate targeted response. As cancer cells present biochemical differences from normal cells; their resonant energies for eliciting biophysical responses are expected to be different. The biochemical properties arising from oncogenic heterogeneity [37] account for the altered physical properties of cancer cells [38]. This allows for distinct electromagnetic interactions [39] and responses in cancer cells as compared to normal cells. The challenge involved finding sharp resonances for biological objects like cells containing a large variety of different macromolecules making it a difficult task. Even if such resonances are 
found in vitro they may change in vivo. The advantages of using the sweeping regime for MMW exposure as described here and in our previous report [19] overcomes this problem by excluding the necessity for fine tuning the irradiation setup operating in vitro. The quasi-optic processes in this range of frequencies can produce either constructive or destructive interference conditions. Sweeping through the $\mathrm{W}$-band $(75-105 \mathrm{GHz})$ of frequencies produces both cases of interference but allows for the constructive points to contribute to the effects observed and reported here.

\section{Conclusion}

Non-thermal, low intensity MMW irradiation in the 75-105 GHz range was shown to specifically affect lung cancer cells without adversely affecting immortalized MCF-10A cells. Irradiation of H1299 cells for 10 minutes resulted in cell death a few days later, while healthy MCF10A cells remained unaffected even after prolonged irradiation for 16 minutes. The experiments demonstrate that appropriately tuned W-band (75-105 GHz) MMW treatment can selectively cause lung cancer cell death in vitro. Our study is the first to use the sweeping regime in the $\mathrm{W}$-band $(75-105 \mathrm{GHz}) \mathrm{MMW}$ frequency range for treatment of cancer cells. This technique of irradiation uses a sweeping spectral regime rather than discrete frequencies providing an integrated effect and has never been investigated in previous studies which used discrete frequency regimes only [40, 41]. Torsional Eigen modes of axially symmetric biomolecules such as carbohydrates, proteins and DNA are likely the reason for the observed power absorption [22]. Estimates based on direct measurements of torsional mode constants place the Eigen frequency for carbohydrates around $70 \mathrm{GHz}$ within the MMW spectrum [42]. Our hypothesis is that under W-band $(75-105 \mathrm{GHz}) \mathrm{MMW}$ irradiation with low energy dosage, one part of the H1299 cell populations tried to repair the damage without success activating pro-apoptotic mechanisms which promoted and resulted in mortality. Some of the cells succeeded to repair the damage and continued dividing and a third group of cells with irreparable damage and incomplete repair promoted a cell senescence mechanism increasing the formation of polyploidy cells. Un-repaired cellular damages, especially in infrequently dividing cells, can accumulate and cause progressive blockage of transcription, loss of gene expression capability and ultimately aging of the cells. Illustratively, changes in DNA conformation or in DNA-protein bonds have been observed corresponding to sharp frequency resonances in the MMW bandwidth [43].

Clinical adaptation of this treatment is limited by the current unavailability of noninvasive devices operating in this bandwidth. Overcoming the low penetration depth of MMW in biological tissue, pulsed irradiation regimes operating within safety limits [44] enables deeper penetration and is a potential approach for further development of devices operating in MMW spectrum. This study demonstrates W-band (75 - $105 \mathrm{GHz}$ ) MMW irradiation delivering an extended energy dosage over 10 minutes effectively terminates H1299 human lung cancer viability. The technique and parameters of using W-band (75 - $105 \mathrm{GHz}) \mathrm{MMW}$ therapy to target H1299 cancer cells specifically without affecting healthy non - tumorigenic MCF-10A epithelial cells encourages clinical adoption of this method as an effective treatment for lung cancer.

Author Contributions: Conceptualization, K.K., J.L., A.Y. and S.L-A.; software, K.K., K.I., A.B. and S.LA.; validation, K.K., K.I and S. L-A.; formal analysis, K.K., K. I., A.B. and S.L-A.; investigation, K.K., K.I. and S.L-A.; resources, K.K., J.L. A.Y. and S.L-A.; data curation, K.K., A.Y., J.L. and S. L-A; writingoriginal draft preparation, K.K., A.B. and S.L-A.; writing-review and editing, K.K., A.Y., A.B. and S.L-A; visualization, K.K. ,K.I., A.B. and S.L-A.; supervision, S.L-A.; project administration, A.Y. and S. L-A.; funding acquisition, K.K., J.L., A.Y. and S.L-A. 
Funding: This research was funded by the Ariel Applied Cancer Research Grant and the Eva and Henry Frankel Foundation (Denmark).

Acknowledgments: We are grateful for very useful discussions with Prof. H. G. Bohr and Prof. Kapilevich B. for the help with the irradiated experiments. We are also grateful for the H1299 cells provided by Professor Uri Alon and MFA10A cells provided by Professor Yossi Shaul, both of the Weizmann Institute of Science, Rehovot, Israel

Conflicts of Interest: The authors declare no conflict of interest.

\section{References}

1. Jemal, A. et al., 2009. Cancer Statistics, 2009. CA: A Cancer Journal for Clinicians, 59(4), pp.225-249. doi: http://www.ncbi.nlm.nih.gov/pubmed/19474385.

2. Jemal, A. et al., 2010. Cancer Statistics, 2010. CA: A Cancer Journal for Clinicians, 60(5), pp.277-300. doi: http://www.ncbi.nlm.nih.gov/pubmed/20610543.

3. Faraonio, R. et al., 2000. Characterization of cis-acting elements in the promoter of the mouse. , Eur J Biochem. 2000 Mar;267(6):1743-53. doi:

https://www.ncbi.nlm.nih.gov/pubmed/10712606

4. Greulich, H., 2010. The Genomics of Lung Adenocarcinoma: Opportunities for Targeted Therapies. Genes \& Cancer, 1(12), pp.1200-1210. Available at: http://gan.sagepub.com/lookup/doi/10.1177/1947601911407324.

5. Wao, H. et al., 2013. Survival of patients with non-small cell lung cancer without treatment: a systematic review and meta-analysis. Systematic reviews, 2, p.10.

Available at: http://www.pubmedcentral.nih.gov/articlerender.fcgi?artid=3579762\&tool=pmcentre $z \&$ rendertype $=$ abstract.

6. Apollonio, F. et al., 2013. Feasibility for microwaves energy to affect biological systems via nonthermal mechanisms: A systematic approach. IEEE Transactions on Microwave Theory and Techniques, 61(5), pp.2031-2045.

7. Paffi, a et al., 2010. Considerations for Developing an RF Exposure System: A Review for in vitro Biological Experiments. Ieee Transactions on Microwave Theory and Techniques, 58(10), pp.2702-2714. Available at: <Go to ISI >://000283440900019.

8. Pakhomov, A.G. et al., 1997. Search for frequency-specific effects of millimeter-wave radiation on isolated nerve function. Bioelectromagnetics, 18(4), pp.324-34. Available at: http://www.ncbi.nlm.nih.gov/pubmed/9140663.

9. Alekseev, S.I. \& Ziskin, M.C., 1999. Effects of millimeter waves on ionic currents of Lymnaea neurons. Bioelectromagnetics, 20(1), pp.24-33. Available at: http://www.ncbi.nlm.nih.gov/pubmed/9915590.

10. Alekseev, S.I. \& Ziskin, M.C., 2003. Local heating of human skin by millimeter waves: a kinetics study. Bioelectromagnetics, 24(8), pp.571-81. Available at: http://www.ncbi.nlm.nih.gov/pubmed/14603477.

11. Krajnik, M. et al., 2010. Local pulmonary opioid network in patients with lung cancer: A putative modulator of respiratory function. Pharmacological Reports, 62(1), pp.139149 .

12. Maneckjee, R. \& Minna, J.D., 1994. Opioids induce while nicotine suppresses apoptosis in human lung cancer cells. Cell Growth \& Differentiation, 5(10), pp.10331040.

13. Radzievsky, a. a. et al., 2004. Millimeter wave-induced suppression of B16 F10 melanoma growth in mice: Involvement of endogenous opioids. Bioelectromagnetics, 25(6), pp.466-473. Available at: http://doi.wiley.com/10.1002/bem.20018.

14. Beneduci, A. et al., 2005. Transmission electron microscopy study of the effects produced by wide-band low-power millimeter waves on MCF-7 human breast cancer 
cells in culture. Anticancer Res, 25, pp.1009-1013. Available at: http://ar.iiarjournals.org/content/25/2A/1009.long.

15. Beneduci, a. et al., 2007. Antiproliferative effect of millimeter radiation on human erythromyeloid leukemia cell line K562 in culture: Ultrastructural- and metabolicinduced changes. Bioelectrochemistry, 70, pp.214-220.

16. Beneduci, A., Cosentino, K. \& Chidichimo, G., 2013. Millimeter Wave Radiations Affect Membrane Hydration in Phosphatidylcholine Vesicles. Materials, 6(7), pp.2701-2712. Available at: http://www.mdpi.com/1996-1944/6/7/2701/.

17. Zhadobov, M. et al., 2009. Evaluation of the potential biological effects of the $60-\mathrm{GHz}$ millimeter waves upon human cells. IEEE Transactions on Antennas and Propagation, 57(10), pp.2949-2956. Available at: http://ieeexplore.ieee.org/xpls/abs_all.jsp?arnumber=5191131.

18. Logani, M.K. et al., 2006. Effect of millimeter wave irradiation on tumor metastasis. Bioelectromagnetics, 27(4), pp.258-64. Available at: http://www.ncbi.nlm.nih.gov/pubmed/16437545.

19. Komoshvili K, Becker T, Levitan J, Yahalom A, Barbora A, Liberman-Aronov S. Morphological Changes in H1299 Human Lung Cancer Cells Following W-Band Millimeter-Wave Irradiation. Appl. Sci. 2020, 10(9), 3187; Available at: https://doi.org/10.3390/app10093187

20. Webster, M., Witkin, K.L. \& Cohen-Fix, O., 2009. Sizing up the nucleus: nuclear shape, size and nuclear-envelope assembly. Journal of Cell Science, 122(10), pp.14771486. Available at: http://jcs.biologists.org/cgi/doi/10.1242/jcs.037333.

21. Krajcovic M, Overholtzer M. 2012. Mechanisms of Ploidy Increase in Human Cancers : A New Role for Cell Cannibalism Mechanisms of Ploidy Increase in Human Cancers : A New Role for Cell Cannibalism. Cancer research, 72, pp.1596-1601. Available at: http://www.ncbi.nlm.nih.gov/pubmed/22447569.

22. Filippi-Chiela, E.C. et al., 2012. Nuclear morphometric analysis (NMA): screening of senescence, apoptosis and nuclear irregularities. PLoS One, 7(8), p.e42522. Available at: http://www.ncbi.nlm.nih.gov/pubmed/22905142.

23. Webster, M., Witkin, K.L. \& Cohen-Fix, O., 2009. Sizing up the nucleus: nuclear shape, size and nuclear-envelope assembly. Journal of Cell Science, 122(10), pp.14771486. Available at: http://jcs.biologists.org/cgi/doi/10.1242/jcs.037333.

24. Debnath, J., Muthuswamy, S.K. \& Brugge, J.S., 2003. Morphogenesis and oncogenesis of MCF-10A mammary epithelial acini grown in three-dimensional basement membrane cultures. Methods (San Diego, Calif.), 30(3), pp.256-68. Available at: http://www.ncbi.nlm.nih.gov/pubmed/12798140.

25. Campisi, J., 2013. Aging, Cellular Senescence, and Cancer. Annual Review of Physiology, $75(1)$, pp.685-705. Available at: http://www.annualreviews.org/doi/abs/10.1146/annurev-physiol-030212-183653.

26. Junk DJ, Bryson BL, Jackson MW. HiJAK'd Signaling; the STAT3 Paradox in Senescence and Cancer Progression. Cancers 2014, 6(2), 741-755; Available from: https://doi.org/10.3390/cancers6020741

27. Lee, H.O., Davidson, J.M. \& Duronio, R.J., 2009. Endoreplication: polyploidy with purpose. Genes \& Development, 23(21), pp.2461-2477. Available at: http://genesdev.cshlp.org/cgi/doi/10.1101/gad.1829209.

28. Weihua, Z. et al., 2011. Formation of solid tumors by a single multinucleated cancer cell. Cancer, 117(17), pp.4092-4099.

29. Shiroff, V.M., 1998. DNA and Chromosome Damage : A Crucial Non-Thermal Biological Effect of Microwave Radiation An Overview of Studies and Models on the Effect Mechanism. , pp.29-43. 
30. Zhadobov, M. et al., 2006. Interactions between 60-GHz millimeter waves and artificial biological membranes: dependence on radiation parameters. IEEE Transactions on Microwave Theory and Techniques, 54(6), pp.2534-2542. Available at: http://ieeexplore.ieee.org/lpdocs/epic03/wrapper.htm?arnumber=1643582.

31. Titushkin, I. a. et al., 2009. Altered Calcium Dynamics Mediates P19-Derived NeuronLike Cell Responses to Millimeter-Wave Radiation. Radiation Research, 172(6), pp.725736. Available at: http://www.bioone.org/doi/10.1667/RR1760.1.

32. Brosig, M. et al., 2010. Interfering with the connection between the nucleus and the cytoskeleton affects nuclear rotation, mechanotransduction and myogenesis. The international journal of biochemistry \& cell biology, 42(10), pp.1717-28. Available at: http://www.ncbi.nlm.nih.gov/pubmed/20621196.

33. Ramundo-Orlando, A., 2010. Effects of Millimeter Waves Radiation on Cell Membrane - A Brief Review. Journal of Infrared Millimeter and Terahertz Waves, 31(12), pp.1400-1411.

34. Beneduci, A. et al., 2012. Microwave induced shift of the main phase transition in phosphatidylcholine membranes. Bioelectrochemistry (Amsterdam, Netherlands), 84, pp.18-24. Available at: http://www.ncbi.nlm.nih.gov/pubmed/22082754.

35. Siegel, P.H. \& Pikov, V., 2010. Impact of low intensity millimetre waves on cell functions. Electronics Letters, 46(26), p.S70. Available at: http://digitallibrary.theiet.org/content/journals/10.1049/el.2010.8442.

36. Szabo, I. et al., 2006. Millimeter wave induced reversible externalization of phosphatidylserine molecules in cells exposed in vitro. Bioelectromagnetics, 27(3), pp.233-44. Available at: http://www.ncbi.nlm.nih.gov/pubmed/16437546.

37. Burrell, R.A.; Swanton, C. Tumour heterogeneity and the evolution of polyclonal drug resistance. Mol. Oncol. 2014, 8, 1095-1111. Available at: https://www.ncbi.nlm.nih.gov/pubmed/25087573

38. ong, J.-L.; Lan, K.-C.; Jang, L.-S. Electrical characteristics analysis of various cancer cells using a microfluidic device based on single-cell impedance measurement. Sens. Actuators B Chem. 2012, 173, 927-934. Available at: https://www.sciencedirect.com/science/article/abs/pii/S0925400512006211?via\%3Dihu b

39. Garg, A.; Jones, T.; Moss, S.M.; Mishra, S.; Kaul, K.; Ahirwar, D.K.; Ferree, J.; Kumar, P.; Subramaniam, D.; Ganju, R.K.; et al. Electromagnetic fields alter the motility of metastatic breast cancer cells. Commun. Biol. 2019, 2, 303-316. Available at: https://www.ncbi.nlm.nih.gov/pubmed/31428691

40. Karinen, A. et al., 2008. Mobile phone radiation might alter protein expression in human skin. BMC genomics, 9, p.77. Available at:

http://www.pubmedcentral.nih.gov/articlerender.fcgi?artid=2258283\&tool=pmcentre z\&rendertype $=$ abstract.

41. $\mathrm{Xu}, \mathrm{S}$. et al., 2010. Exposure to $1800 \mathrm{MHz}$ radiofrequency radiation induces oxidative damage to mitochondrial DNA in primary cultured neurons. Brain research, 1311, pp.189-96. Available at: http://www.ncbi.nlm.nih.gov/pubmed/19879861.

42. W. K. Olson, A. R. Srinivasan, A. V. Colasanti, G. Zheng, D.S., 2009. DNA Biomechanics. In Henrik G. Bohr, ed. Handbook of Molecular Biophysics : Methods and Applications. Wiley, p. 1074.

43. Belyaev, I.Y. et al., 1993. Evidence for Dependence of Resonant Frequency of Millimeter Wave Interaction with Escherichia coli K12 Cells on Haploid Genome Length. Electro- and Magnetobiology, 12(1), pp.39-49. Available at: http://www.tandfonline.com/doi/full/10.3109/15368379309012861.

44. Furman O, Komoshvili K, Levitan J, Yahalom A, Marks H, Borodin D, Liberman- 
Aronov S. The Lack of Toxic Effect of High-Power Short-Pulse $101 \mathrm{GHz}$ Millimeter Waves on Healthy Mice. Bioelectromagnetics. 2020 Apr;41(3):188-199. doi:

Waves on Healthy
$10.1002 /$ bem.22247. 